\title{
Using ABAQUS Finite Element Analysis to Investigate the Influence of FRP Types and Reinforcement Ratio on Flexural Capacity of Beams Reinforced with FRP Rod
}

\author{
Aboubieda Alamin Ahmed Almansoor \\ Hubei Key Laboratory of Roadway Bridge and Structure \\ Engineering, Wuhan University of Technology \\ Wuhan, 430070, China \\ E-mail: abuo_ahmed2001@yahoo.com
}

\author{
Jianwei TU \\ Hubei Key Laboratory of Roadway Bridge and Structure \\ Engineering, Wuhan University of Technology \\ Wuhan, 430070, China \\ E-mail: Waider1@163.com
}

\begin{abstract}
GFRP bars are non corrosion materials, their tensile modulus relatively are lower compared with steel reinforcement. A total of six beam specimens (BG1 BG3 and $\mathrm{BC} 1 \mathrm{BC} 3)$ were simulated to failure by concrete crushed under four-point bending. The main parameters studies were FRP reinforcement's types (GFRP and CFRP) bars and amounts of reinforcement ratios. To compare the influence of these parameters on the flexural behavior of FRPs concrete beams, ABAQUS Finite-element software was used. The results showed that; with increasing of reinforcement ratio, bearing capacities for all beams were increased. All of GFRP specimens have a larger mid span deflection than CFRP beams. In all FRP specimens, mid span deflection were decreased with increased as the reinforcement ratio, this decreased is larger in GFRP bars than that in CFRP specimens.
\end{abstract}

Keywords-ABAQUS; finite element analysis; FRP bars; concrete crushing failure

\section{INTRODUCTION}

Corrosion of steel bars in aggressive environments can cause considerable damage in reinforced concrete[1], and is caused by chloride's ions[2], Chlorides and carbonation[3].

Fiber-reinforced polymers(FRP) bars are non-corrosive materials[4]used instead of the steel bars to prevent the drawbacks related to steel reinforcement[5] and enhance the reinforced concrete structures to corrosion resistance. Generally, FRP consists of synthetic or organic highstrength fibers in a resin matrix and mostly divided into three common types used in civil engineering application's fields. Those are Carbon fiber (CFRP), Aramid fiber (AFRP) and Glass fiber (GFRP)[6].

FRP bars have a different mechanical property than steel bars; involve a high-tensile strength combination with low elastic modulus and elastic brittle stress-strain relationship. Because of their linear elastic brittle behavior, the flexural exhibits no ductility[7].

Abdul Rahman et al. [8] Presents the performance of concrete beams reinforced with different types of Glass fiber reinforced polymer section. From their research, it was made a comparison with a control beam on the aspect of load-deflection behavior, ultimate load, mode of failure and load reinforced strain behavior. Their experimental results showed that the beams reinforced with GFRP sections estimated lower stiffness, lower load carrying capacity, fewer numbers of cracks and large deflection.
The developed of finite element with computer technology, get a large knowledge and improved of finiteelement analysis using the software.

ABAQUS finite-element software is one of the large common finite-element analysis software useing in scientific research field and engineering applications. That is because, not only has a fast calculation of numerical analysis results, high precision and low cost advantage, but also has more humanized interface and visual results, specialized in non-linear analysis of reinforced concrete structure field, which can get more accurate results [9].

The purpose of this study is to investigate the affect of reinforcement ratio and FRP types on the ultimate capacity and mid span deflection by using ABAQUS finite element software.

\section{THE BEAM MODEL}

Three GFRP specimens and three specimens of CFRP RC beams were simulated. The beam specimen was designated as BG\# and BC\#. B stands for beam; \# is the specimen number; while $\mathrm{G}$ and $\mathrm{C}$ are referred to GFRP and CFRP rebar, respectively. The beams were $150 \mathrm{~mm}$ wide, $250 \mathrm{~mm}$ high, $2550 \mathrm{~mm}$ long, with the distance between the end-supports being $2300 \mathrm{~mm}$. All beams were tested under four-points loading. The shear span was $767 \mathrm{~mm}$ (one third of the beam span). Steel stirrups reinforcement were used at the shear span to avoid the shear failure, while the mid span was left free of stirrups. Nominal $6 \mathrm{~mm}$ GFRP or CFRP were used at the top with in the shear span to hold the stirrups. $25 \mathrm{~mm}$ was used as the concrete cover in all of specimens. The geometric and reinforcement details of this analytical beams test are shown in Fig. 1 and table 1, while Table 2 and 3 showed the material properties of bars FRP and concrete respectively.

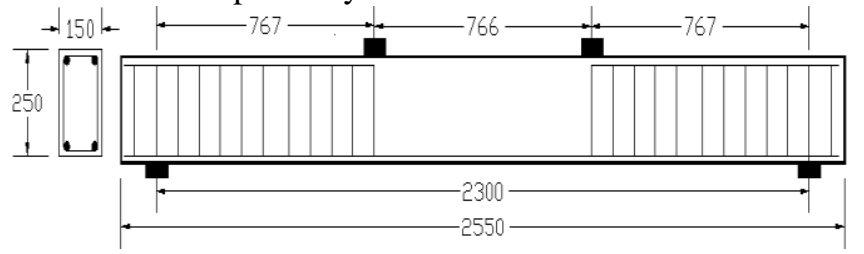

Figure1. Geometric and reinforcement details of the beam model 
TABLE I. TABLE REINFORCEMENT DETAILS OF FRP

\begin{tabular}{|c|c|c|}
\hline Specimens & Tensile rebars & Reinforcement ratios \\
\hline BG1 & $2 \phi 9.53$ & 0.00432 \\
\hline BG2 & $2 \phi 12.7$ & 0.00772 \\
\hline BG3 & $4 \phi 19.05$ & 0.03910 \\
\hline BC1 & $3 \phi 6.35$ & 0.00286 \\
\hline BC2 & $3 \phi 9.53$ & 0.00648 \\
\hline BC3 & $3 \phi 12.7$ & 0.011600 \\
\hline
\end{tabular}

\section{METHODOLOGY}

All of the beams were simulated under four-points loading Fig. 2. The load was applied, firstly, by a $50 \mathrm{kN}$ on each of Blocks point by mean of $(\mathrm{P} / 2=25 \mathrm{kN})$, then the load was increased at rate of $10 \mathrm{kN} /$ time and after each times, maximum load was measured according to the applied load. In ABAQUS finite element software, the load should be applied by mean of the vertical displacement (U2-m; where 2 refer to y direction) instead of concentrated load $(\mathrm{P}-\mathrm{kN})$, and the displacements (deflections) were obtained directly according to this value of the Load. That is because of; the result does not convergence when we applied load directly by means of concentrated load $(\mathrm{P}-\mathrm{kN})$. Two elements were putted on the beam mid-span location; one at the beam top to measuring the concrete compressive stress-strain and the other one putted on the tensile reinforcement bars to measuring the stress-strain of FRP rebar. After each time of loading, the strain and stress values for both of compressive concrete and tensile bar were measured until failure occurred; either by rupture of bars or crushing of concrete Fig. 3 and 5.

TABLE II. TABLE TENSILE PROPERTIES OF FRP REBAR

\begin{tabular}{|c|c|c|c|c|}
\hline Rebar type & \multicolumn{2}{|c|}{$\phi^{a}(\mathbf{m m})$} & $E_{f}{ }^{b}(\mathbf{M p a})$ & $f_{f u}{ }^{c}(\mathbf{M p a})$ \\
\hline \multirow{4}{*}{ GFRP } & BG1 & 9.53 & 40800 & 760 \\
\cline { 2 - 5 } & BG2 & 12.7 & 40800 & 690 \\
\cline { 2 - 5 } & BG3 & 19.05 & 40800 & 620 \\
\hline \multirow{5}{*}{ CFRP } & BC1 & 6.35 & 119750 & 1250 \\
\cline { 2 - 5 } & BC2 & 9.53 & 122750 & 1000 \\
\cline { 2 - 5 } & BC3 & 12.7 & 111750 & 900 \\
\hline
\end{tabular}

a. Diameter bar. b. FRP elastic modulus. c. FRP tensile stress.

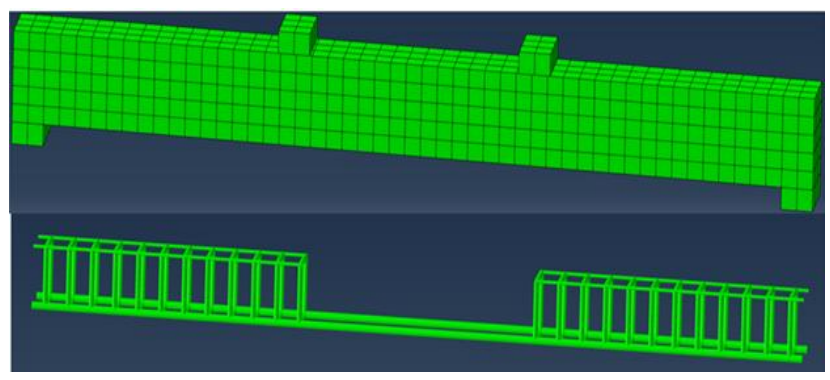

Figure 2. Finite element model for concrete and FRP reinforcement
TABLE III.

TABLE CONCRETE PROPERTIES[10]

\begin{tabular}{|c|c|c|c|c|}
\hline$f_{c u}^{d}(\mathbf{M p a})$ & $f_{c}^{e}(\mathbf{M p a})$ & $f_{t}^{f}(\mathbf{M p a})$ & $E_{c}^{g}(\mathbf{M p a})$ & $v_{c}^{h}$ \\
\hline$C^{j} 30$ & 14.3 & 1.43 & 30000 & 0.2 \\
\hline
\end{tabular}

d. Concrete strength. e. Concrete compression strength. f. Concrete tensile strength. g. Elastic modulus of concrete. h. Concrete poison's ratio.

\section{ANALYTICAL RESULtS}

\section{A. Concrete Crushing and FRP Rupture}

Theoretically, reinforced concrete beams can be designed for tension, balanced or compression failure mode for required ultimate bending moment. Traditionally, concrete beams with steel reinforcement are designed for tension failure to take advantage of elastic plastic behavior of steel. Unlike steel, GFRP reinforcement has a linear stress-strain behavior until to failure. In case of concrete crushing failure mode, $\varepsilon_{c}=\varepsilon_{c u}=0.0035$ (where; $\varepsilon_{c}$ is compression concrete strain, $\varepsilon_{c u}$ is ultimate concrete strain) Fig. 5. But for the case of GFRP tensile rupture $\varepsilon_{f}=\varepsilon_{f u}$ and $\varepsilon_{c}=0.0035$ (where; $\varepsilon_{f}$ is GFRP bars tensile strain, $\varepsilon_{f u}$ is GFRP bars ultimate tensile strain) Fig. 3. In Fig. 4 can be observed that; FRP bars were reached the ultimate tensile stress (1250Mpa) in the tensile region, while in the compression region, the stress of FRP bars is much smaller than tensile region, because of FRP bars were bearing by small force in this place, so there is small stress. The concrete should failed when the compressive strength $(\mathrm{C} 30=14.3 \mathrm{Mpa})$ reached its maximum compressive stress (13.2 15.85 Mpa) Fig. 6, it also can observed; the maximum Misses stress value between 13.21 to $15.85 \mathrm{Mpa}$ in compression zone, while the minimum Misses stress achieved in the tension zone is around $1.338 \mathrm{Mpa}$, indicated that; this regions were bearing by small force, so it have a smaller stress than compression zone.

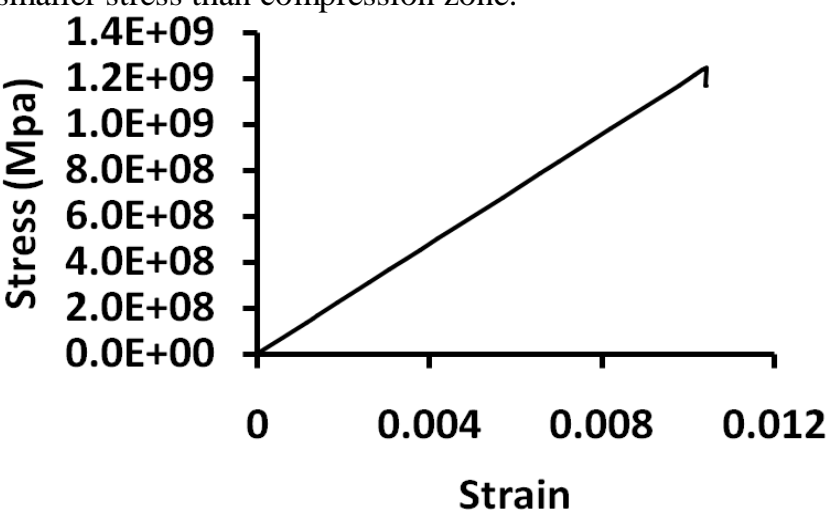

Figure 3. FRP stress-strain curve $(\mathrm{BC} 1)$ specimen 


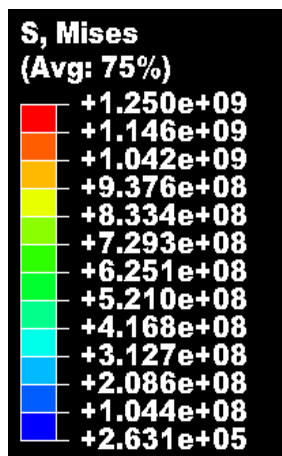

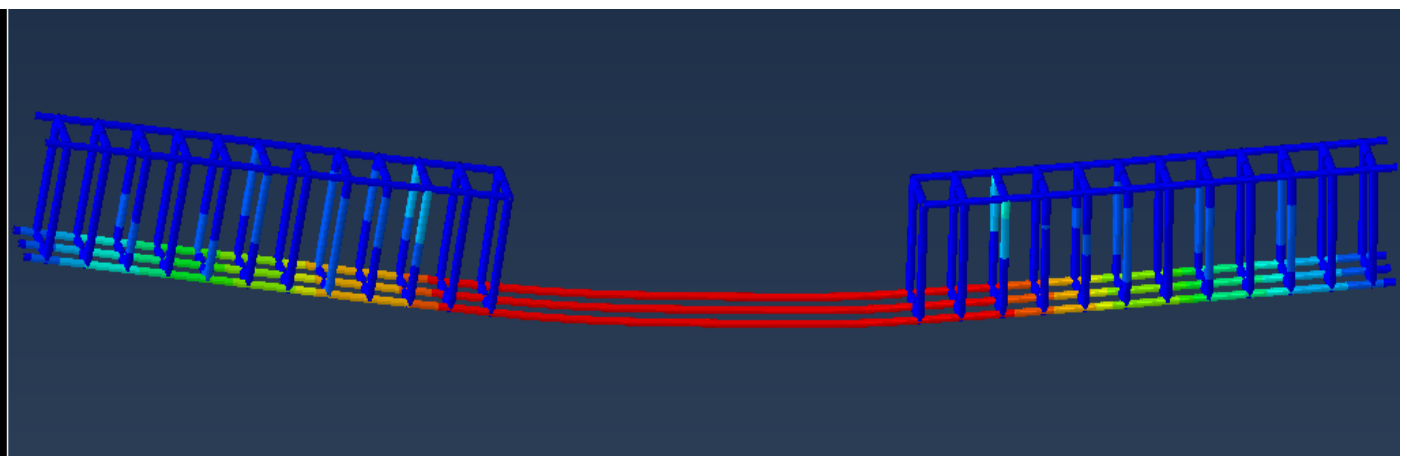

Figure 4. FRP F.E failure mode (BC1) specimen

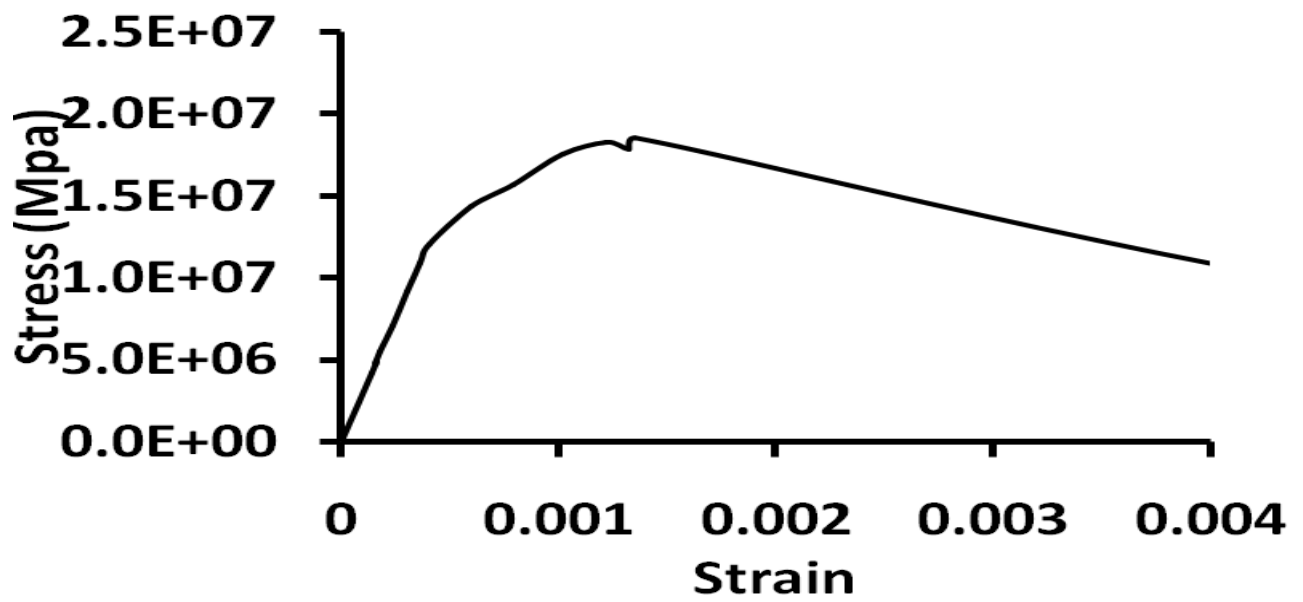

Figure 5. Concrete stress-strain curve (BC2) specimen

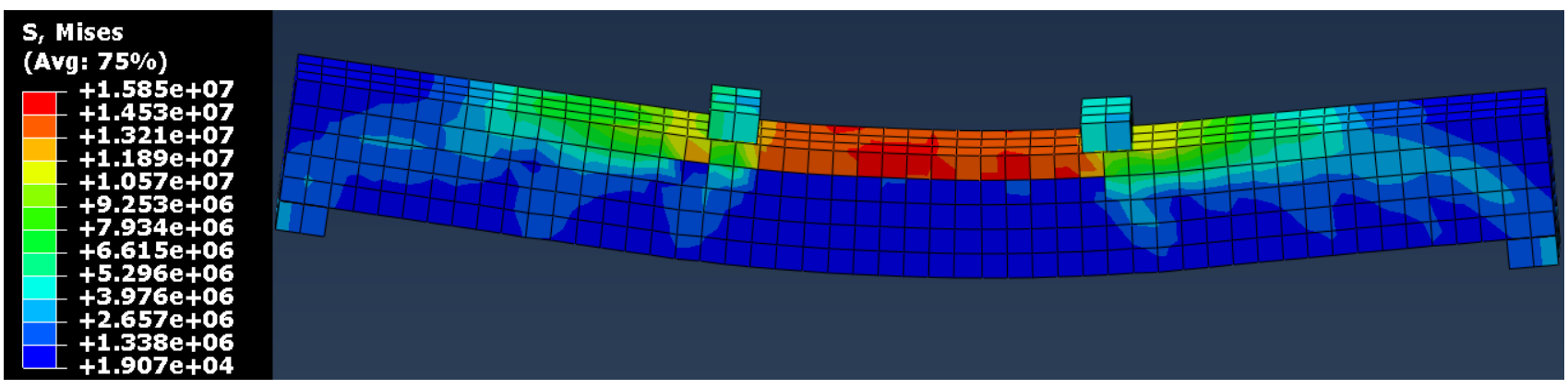

Figure 6. Concrete F.E failure mode (BC2) specimen

\section{B. Affect of Reinforcement Ratio to Bearing Capacity}

Fig. 7 and 8 show the analysis results of Load-deflection response at mid span for $\mathrm{BC}$ and $\mathrm{BG}$ specimens respectively. From these figures, it is clear that; the results of the two replicate beams within each series are rather identical. The loads to mid span deflection curves were bilinear for all beam specimens. The first part of these curves up to crack represents the behavior of un-cracked beams. When the cracking load is achieved, a drop in the slope is observed with reduced of stiffness. Finally, the cracking process stabiles and almost linear segment is observed until failure. The reinforcement ratios had an effective on the stiffness of the beam specimens and, therefore, on their load-deflection behavior. As expected, larger deformations are obtained for the lower reinforcement ratio. It can also be observed that the deflections at mid span in concrete beams with GFRP in all of specimens are larger than that in CFRP specimens at the same load. This indicates that for the same area of reinforcement, GFRP bars have a different behavior than CFRP. Increasing of deflection in GFRP bars compared with CFRP at the same load also indicates to the low stiffness of the member and vice versa. Stiffness is calculated as load per unit deflection. Increased the deflection in GFRP bars compared with CFRP bars also may be because of the low elastic modulus of GFRP bars, this result is a similar conclusion has been introduced by Ilker and Ashour.[11]. At $50 \mathrm{kN}$ load, the mid span deflections were 70,40 , and $10 \mathrm{~mm}$ for specimens BG1, BG2, and BG3, respectively (see Fig. 8), could be revealed 
that increasing the reinforcement ratio from 0.00432 to 0.0391 . However, increases the ultimate capacity from 53 $\mathrm{kN}$ to $78 \mathrm{kN}$ led to decreased of mid span deflection from 70 to $10 \mathrm{~mm}$, while at the same load $(50 \mathrm{kN})$, the mid span deflections were 35,15 , and $10 \mathrm{~mm}$ for specimens $\mathrm{BC} 1$, $\mathrm{BC} 2$, and BC3, respectively (see Fig. 7), could be revealed that increases the reinforcement ratio from 0.00286 to 0.0116 , led to increases the ultimate capacity from $60 \mathrm{kN}$ to $80 \mathrm{kN}$ and decreased of mid span deflection from 35 to 10 $\mathrm{mm}$.

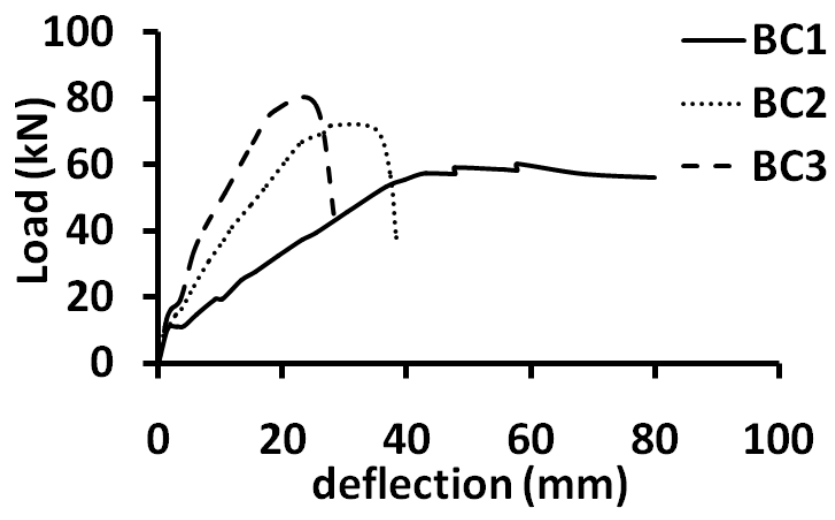

Figure 7. Load-deflection (BC)

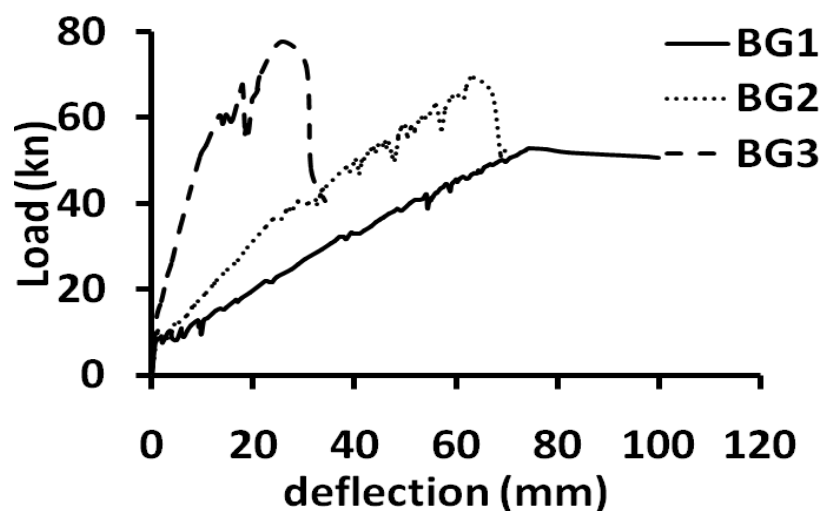

Figure 8. Load- deflection (BG)

\section{Effect of FRP Types}

Fig. 9 represents the load-deflection relationships of FRP reinforcement with different types of FRP bars (BG1 and $\mathrm{BC} 1)$ specimens. From this figure can observe that; the beams reinforced with GFRP bars (BG1) exhibit a significant reduction in stiffness after the initiation of first crack in comparison with CFRP (BC1) reinforcement. This behavior is attributed to the low elastic modulus of GFRP bars compare with CFRP bars, which affects to the ability of GFRP bars to control concrete cracks, lead to a decreased effective moment of inertia and hence large deflections.

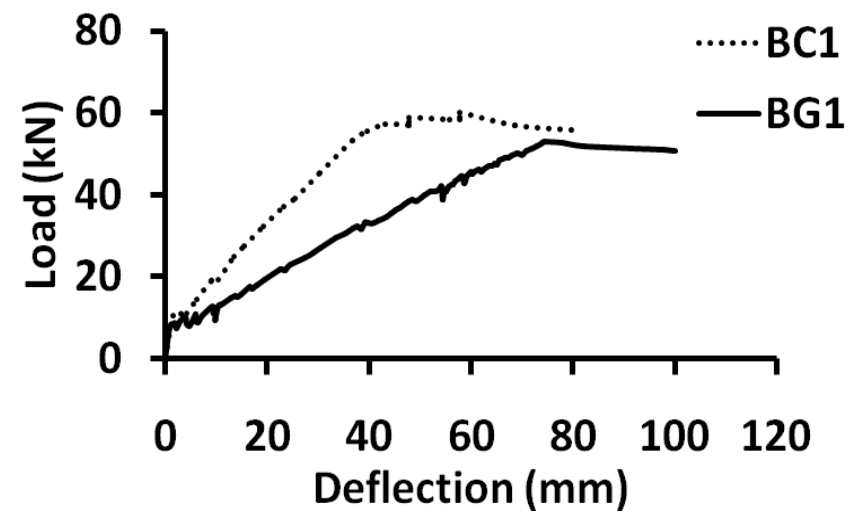

Figure 9. Load-deflection (BG1, BC1) specimens

\section{CONCLUSION}

- The load-deflection curves were bilinear for all of specimens and is divided in to three parts; the first part up to cracking represents the behavior of uncracked beam, the second part represents the behavior of the beam's cracked with reduced of stiffness, while the third part, which is come down was represents to failure of specimen.

- Increasing the reinforcement ratio from 0.00432 to 0.0391 for series BG (Fig. 8), tends to increase the ultimate capacity from $53 \mathrm{kN}$ to $78 \mathrm{kN}$ respectively, while increases the reinforcement ratio from 0.00286to 0.0116, however, tends to increase the ultimate capacity from $60 \mathrm{kN}$ to $80 \mathrm{kN}$ respectively Fig. 7).

- The deflections at mid span in all of concrete beams reinforced with GFRP are larger than that in CFRP specimens at the same load. Indicated that to the low elastic modulus of GFRP bars compared with CFRP and low stiffness of GFRP member than that in CFRP.

- Beams reinforced with GFRP bars exhibit a significant reduction in stiffness after the initiation of the first crack in comparison with CFRP reinforcement with the same reinforcement ratios (see Fig. 9).

- All of the beams were failed by concrete crushing at compression zone except (BC1) specimen (Fig. 4) which was failed due to the rupture of FRP reinforcement. This is not recommended because it may results in catastrophic failure of the structures.

\section{ACKNOWLEDGEMENT}

A. Almansoor gratefully acknowledges the Chinese Scholarship Council (CSC) for funding this $\mathrm{PhD}$ research. Also he would like to thank Wuhan University of Technology for providing a lot of information's facilities to conduct this article.

\section{REFERENCES}

[1] C.Barris, L. Torres, A. Turon, M. Baena, and A. Catalan, "An experimental study of the flexural behaviour of GFRP RC beams and 
comparison with prediction models," Composite Structures, vol. 91, pp. 286-295, 2009.

[2] M. A. Adam, M. Said, A. A. Mahmoud, and A. S. Shanour, "Analytical and experimental flexural behavior of concrete beams reinforced with glass fiber reinforced polymers bars," Construction and Building Materials, vol. 84, pp. 354-366, 2015.

[3] G. Nkurunziza, A. Debaiky, P. Cousin, and B. Benmokrane, "Durabilityof GFRP bars: a critical review of the literature," Progress in structural engineering and materials, vol. 7, pp. 194-209, 2005.

[4] I. Chitsazan, M. Kobraei, M. Z. Jumaat, and P. Shafigh, "Anexperimental study on the flexural behavior of FRP RC beams and a comparison of the ultimate moment capacity with ACI," Journal

[5] S. H. Alsayed, "Flexural behaviour of concrete beams reinforced with GFRP bars," Cement and Concrete Composites, vol. 20, pp. 1-11, 1998.
[6] B. Benmokrane, O. Chaallal, and R. Masmoudi, "Glass fibre reinforced plastic (GFRP) rebars for concrete structures," Construction and Building Materials, vol. 9, pp. 353-364, 1995.

[7] M. S. Issa, I. M. Metwally, and S. M. Elzeiny, "Influence of fibers on flexural behavior and ductility of concrete beams reinforced with GFRP rebars," Engineering Structures, vol. 33, pp. 1754-1763, 2011.

[8] A. R. M. Sam, S. A. Hassan, and T. S. Thye, "Glass Fibre Reinforce Polymer Structural Selection as Concrete Beam Reinforcement," Malaysian Journal of Civil Engineering, vol. 15, pp. 16-23, 2003.

[9] S. Deng, Z. Qie, and L. Wang, "Nonlinear Analysis of Reinforced Concrete Beam Bending Failure Experimentation Based on ABAQUS," in First International Conference on Information Sciences, Machinery, Materials and Energy, 2015. [In Chinese]

[10] G., "Code for design of concrete structures [S]," 2010. [In Chinese]

[11] I. F. Kara and A. F. Ashour, "Flexural performance of FRP reinforced concrete beams," Composite Structures, vol. 94, pp. 1616-1625, 2012. 